\title{
ALEITAMENTO MATERNO E PASTORAL DA CRIANÇA: UMA ANÁLISE
}

\author{
DOCUMENTAL
}

\author{
Gabriele Alves de Paula Chemin ${ }^{1}$ \\ Suzelaine Taize Stadler ${ }^{2}$ \\ Elaine Cristina de Oliveira ${ }^{3}$ \\ César Rey Xavier ${ }^{4}$ \\ Cristina Ide Fujinaga ${ }^{5}$
}

Recebido em: 06 mar. 2018 Aceito em: 13 nov. 2018

RESUMO: O artigo faz uma análise crítica documental do material impresso utilizado pelas líderes da Pastoral da Criança, sobre o aleitamento materno. A natureza do estudo é qualitativa, utilizando o método de análise de conteúdo do tipo temática e estrutural, a partir da análise documental. $O$ material analisado reforça o conhecimento científico e a função biológica do aleitamento materno, homogeneizando as ações e descontextualizando a ação local e comunitária. A organização da Pastoral em grupos pequenos favorece o trabalho de apoio ao aleitamento materno, porém há muito que considerar sobre o papel singular de cada líder além do que está posto nos materiais padronizados pela instituição.

Palavras-chave: Aleitamento materno. Organização comunitária. Políticas públicas.

\section{BREASTFEEDING AND PASTORAL OF THE CHILD: A DOCUMENTAL ANALYSIS}

\begin{abstract}
The article makes a documentary critical analysis of printed material used by leaders of the Pastoral on breastfeeding. The nature of the study is qualitative, using the method of analysis of content of thematic and structural type, from the documentary analysis. The analyzed material reinforces the scientific knowledge and the biological function of breastfeeding, homogenizing actions and decontextualizing local and community action. The Pastoral organization in small groups favors the work in support of breastfeeding, but there is much to consider about the unique role of each leader beyond what is laid on standardized materials by the institution.

Keywords: Breast feeding. Communitarian organization. Public policies.
\end{abstract}

\footnotetext{
${ }^{1}$ Gabriele Alves de Paula Chemin, Mestra em Desenvolvimento Comunitário pela Universidade Estadual do Centro-Oeste/UNICENTRO, gabiapaula@yahoo.com.br.

2 Suzelaine Taize Stadler, Mestra em Desenvolvimento Comunitário pela Universidade Estadual do CentroOeste/UNICENTRO, fonoaudiologasuzelaine@hotmail.com.

${ }^{3}$ Elaine Cristina de Oliveira, Profa. Dra. do Departamento de Fonoaudiologia -Universidade Federal da Bahia/UFBA, elaineoliveira1009@gmail.com.

4 César Rey Xavier, Prof. Dr. do Departamento de Psicologia - Universidade Estadual do CentroOeste/UNICENTRO, Vice-Coordenador do Mestrado Interdisciplinar em Desenvolvimento Comunitário PPGDC, reyxavier@gmail.com.

${ }^{5}$ Cristina Ide Fujinaga, Profa. Dra. do Departamento de Fonoaudiologia - Universidade Estadual do CentroOeste/UNICENTRO, Coordenadora do Programa de Pós-Graduação Interdisciplinar Desenvolvimento Comunitário Universidade Estadual do Centro-Oeste/UNICENTRO, cifujinaga@gmail.com.
} 


\section{INTRODUÇÃO}

Os benefícios do aleitamento materno, tanto para a saúde infantil, quanto para a saúde da mulher, têm sido amplamente difundidos na literatura. Entretanto, embora se tenha este reconhecimento científico, o incentivo e a manutenção desta prática são dependentes de diversos fatores que envolvem questões culturais, práticas dos serviços de saúde e principalmente o apoio às mulheres/mães através de políticas públicas que Ihes forneçam suporte adequado para a manutenção do aleitamento materno até a idade sugerida pela Organização Mundial da Saúde. A fim de mudar este cenário e promover o aleitamento materno, algumas instituições realizam ações comunitárias a fim de superar tal situação (AKRÉ, 1994).

Entre as ações comunitárias em curso podemos destacar aquelas que são realizadas pela Pastoral da Criança, cuja organização comunitária é de âmbito nacional e tem por finalidade realizar um trabalho voltado ao desenvolvimento integral de crianças no contexto familiar e comunitário, além de promover e apoiar o aleitamento materno (PASTORAL DA CRIANÇA, 2003). A pessoa responsável por realizar o acompanhamento das famílias é denominada líder comunitária e participa de uma capacitação antes de iniciar as visitas.

As atividades desenvolvidas pelas líderes comunitárias são compreendidas como um investimento na mulher enquanto mãe. As líderes desenvolvem esse investimento a partir do acompanhamento das gestantes, dos filhos e de toda a família (ANJOS, 2007), empregando o uso de alguns materiais impressos, os quais serão especificados mais a seguir. Em relação ao aleitamento materno, as líderes desenvolvem atividades durante a gestação para preparar as mães para a amamentação, realizam orientações sobre a importância do aleitamento materno exclusivo até o 6ํำ e a manutenção até os dois anos ou mais (PASTORAL DA CRIANÇA, 2015).

Percebe-se que, na prática cotidiana, as capacitações oferecidas às líderes são realizadas por profissionais de saúde cujos discursos e assistências têm privilegiado uma conduta voltada para os aspectos biológicos e orgânicos do aleitamento materno. Diante disso, este artigo pretende realizar uma análise documental do material impresso sobre o tema aleitamento materno utilizado pelas líderes da Pastoral da Criança.

\section{MATERIAL E MÉTODOS}

Trata-se de um estudo de natureza qualitativa, utilizando o método de análise de conteúdo do tipo temática e estrutural, a partir da análise documental (MINAYO, 2000). Os materiais impressos e padronizados utilizados pelas líderes comunitárias da Pastoral da Criança abordam o desenvolvimento global da criança desde a gestação até os 6 anos de idade. Nessa pesquisa selecionamos apenas os materiais que abordam diretamente o tema do aleitamento materno. Para tal, foram analisados os seguintes materiais: Guia do Líder 
da Pastoral da Criança: para países de língua portuguesa / Pastoral da Criança - 15 ed. Curitiba, 2015.; Caderno do Líder da Pastoral da Criança; Folha de Acompanhamento e Avaliação Mensal das Ações Básicas de Saúde e Educação na Comunidade e o envelope Laços de Amor.

A análise dos dados foi composta por duas etapas: de organização e interpretação dos dados (MINAYO, 2000). Primeiramente, a partir de uma leitura flutuante e avaliação geral, foram selecionados e organizados os materiais que continham algum conteúdo relacionado ao tema aleitamento materno. Posteriormente à seleção, foi realizada uma interpretação minuciosa dos dados sustentada primeiramente por uma concepção de corpo que não pode ser reduzido ao aspecto biológico e que, no sentido foucaultiniano, é constituído por aspectos políticos, sociais e culturais importantes e, segundo, por um modelo de educação em saúde dialógico, integrando partes do sujeito objetivizado pelo olhar reducionista da biomedicina, possibilitando a reconstrução de sentidos e significados, individuais e/ou coletivos, sobre o processo saúde-doença-cuidado (ALVES, 2005).

Todos os materiais analisados neste trabalho foram criados e padronizados para direcionar as visitas domiciliares das líderes comunitárias. O Guia do Líder e o envelope denominado 'Laços de Amor' são os materiais que informam e orientam questões referentes ao aleitamento materno. Os outros materiais citados são utilizados para coleta de dados. Todos os materiais são utilizados conjuntamente pelas líderes.

\section{RESULTADOS E DISCUSSÃO}

\section{GUIA DO LÍDER DA PASTORAL E 'LAÇOS DE AMOR'}

A primeira referência ao aleitamento materno no Guia do Líder aparece na segunda etapa da capacitação, na página 30, que corresponde à primeira visita domiciliar à gestante. Nesse primeiro momento, a líder explica à gestante como devem ser os cuidados nos primeiros mil dias de vida da criança e de que forma eles podem afetar significativamente a saúde do bebê. Além disso, a líder entrega à gestante a primeira ficha do material 'Laços de Amor', com o conteúdo desta primeira visita, contendo cartelas de orientação mensal para a gestante e o bebê (PASTORAL DA CRIANÇA, 2015).

Os primeiros mil dias de vida correspondem a 270 dias de gestação +365 dias do $1^{\circ}$ ano de vida +365 dias do $2^{\circ}$ ano de vida (PASTORAL DA CRIANÇA, 2015). Segundo Cunha (2015) esse é um período muito importante para realizar ações e intervenções que irão repercutir ao longo de toda a vida do indivíduo, tanto em questões nutricionais como em questões afetivas.

O autor complementa que as ações realizadas nesse período "podem aumentar as chances da criança de ter uma vida saudável e produtiva no futuro, fortalecer famílias e comunidades e contribuir para quebrar o ciclo intergeracional da pobreza" (CUNHA, 2015, 
p. 50). Ao abordar esse assunto já no primeiro encontro, as líderes esperam que a gestante conheça essa teoria e planeje os cuidados com seu filho desde a gestação. Esse dado corrobora com alguns estudos como Rios; Vieira (2007), entre outros, que trazem a efetividade e a importância de atividades educativas realizadas durante o período pré-natal.

Sabe-se que durante o período pré-natal, a mulher necessita de cuidados especiais, devido ao fato de vivenciar experiências singulares decorrentes de mudanças fisiológicas, corporais, psicossociais, etc. (SILVA, et al., 2012). Com base nessa demanda, foram criadas algumas políticas públicas a fim de garantir o cuidado integral da mulher, dentre as quais pode-se citar a Política Nacional de Atenção Integral à Saúde da Mulher (BRASIL, 2004). Entretanto, estudos recentes (SILVA, et al., 2012; GONÇALVEZ; CESAR; SASSI, 2009) mostram que, apesar dessas políticas públicas, a maioria dos serviços de assistência de pré-natal no Brasil não é classificado como adequado, do ponto de vista de garantia de assistência integral à gestante, uma vez que frequentemente, essa atenção está voltada a atender as queixas específicas das gestantes, tornando-se uma atenção precária para promover a saúde integral da mãe (GONÇALVEZ, CESAR, SASSI, 2009; COSTA, et al., 2009). Além disso, somente as mulheres empregadas com contrato formal de trabalho têm alguns benefícios garantidos pela Constituição Federal, como a proibição da "demissão sem justa causa ou arbitrária da trabalhadora gestante, dando estabilidade no emprego desde a confirmação da gravidez até cinco meses após o parto" (BRASIL, 2015a, p. 5).

Um estudo realizado por Saliba et al (2008) demonstra que realizar grupos de discussão abordando os mitos, inibições e demonstrações práticas sobre as vantagens da amamentação, envolvendo pessoas do convívio social da mulher são métodos úteis e eficazes que devem ser implementados, reforçando a importância do aleitamento materno. Dessa maneira, observa-se que estratégias para convencer a mulher sobre a importância da amamentação existem, entretanto, chamamos a atenção para o lugar em que se posiciona a mulher. Comumente, coloca-se na mulher a responsabilidade pela saúde $e$ nutrição do seu bebê sem assegurar a ela mecanismos e possibilidades reais para que isso ocorra. Para tanto, devemos analisar a recomendação da Organização Mundial da Saúde (OMS), a qual assevera sobre o "aleitamento materno exclusivo por 6 meses e continuidade da amamentação com a introdução de alimentos complementares até os 2 anos ou mais", algo que vai contra o que é preconizado pela legislação brasileira, na qual a mulher que trabalha sob o regime CLT tem o direito a 120 dias de licença-maternidade, ou seja, ela é responsabilizada pela decisão de desmamar seu filho antes dos 6 meses, em respeito à lei que a obriga a retornar ao trabalho quando seu filho ainda está com quatro meses. Em 2008, a Lei 11.770 (Empresa Cidadã) passou a estender a licença-maternidade para 6 meses, entretanto a mesma garante este direito adquirido apenas para servidores federais e estaduais. Mulheres que estão fora deste sistema dependem da decisão da empresa em que trabalham em optar ou não por seguir tal lei. Também existe, dentro da lei da CLT, no artigo 396, seção $\mathrm{V}$, a recomendação de que a mulher tenha direito a dois intervalos de meia hora por dia, além dos intervalos normais de repouso e alimentação, para que possa utilizá-los para amamentar seu bebê até que ele complete 6 meses de vida. Tal condição 
deve ser combinada com o empregador a fim de flexibilizar o horário, pois algumas mulheres trabalham longe de suas casas, não sendo possível utilizar esse benefício no meio do dia. Vale lembrar que, na realidade, milhares de mulheres estão fora de qualquer condição de trabalho formal, ou seja, não tem garantido nenhum benefício durante os primeiros 6 meses de vida do filho.

Diante disso, infere-se que somente a orientação e conscientização sobre os benefícios da amamentação, iniciada já na fase gestacional, não são suficientes para que a mãe opte e realize o aleitamento materno exclusivo até os seis meses, devendo ser repensadas as políticas públicas de apoio ao aleitamento materno. Como se propõe a demonstrar com estas reflexões, o cumprimento das políticas e direitos das lactantes depende de fatores que vão além da mera formalidade legal ou institucional. $E$ na medida em que tais fatores começam a ser levados em conta, promove-se como consequência uma maior possibilidade de que a responsabilidade das mães não venha carregada da concomitante e infelizmente corriqueira culpabilização das mesmas, no que tange às contingências da amamentação.

Orientações sobre encaminhamentos necessários e questões sociais também fazem parte do Guia do Líder para que a lactante conheça seus direitos e seja incentivada a procurá-los, caso deseje manter o aleitamento materno e encontre barreiras. As orientações da legislação específica do Brasil são sinalizadas com uma bandeira do País, ressaltando que tal orientação só é válida no Brasil, pois o mesmo Guia é utilizado em todos os países de língua portuguesa em que a Pastoral da Criança atua. Acredita-se que caso a mãe estiver sendo acompanhada, ela irá desenvolver a sua autonomia, possibilitando que ela tome decisões baseadas nas suas necessidades reais. Logo, levará a mulher a ter mais saúde e liberdade de escolher e de participar da sua gestação (SILVA, et al., 2012).

Na terceira etapa da capacitação, o Guia do Líder orienta sobre a importância do aleitamento materno, sugerindo que a líder converse com a gestante e seu companheiro sobre suas dúvidas e experiências de amamentação, fazendo referência ao conhecimento social/cultural. Com essa metodologia poder-se-ia esperar que a gestante e seus familiares pudessem participar ativamente do processo de construção do conhecimento, tornando-se protagonistas na opção pelo aleitamento materno. Entretanto, nessa mesma página o guia afirma que tal atitude facilita que as orientações repassadas pela líder sejam ouvidas e colocadas em prática, permanecendo o modelo de orientação depositária também chamada por Freire (1983) de concepção bancária, onde o indivíduo que está na posição de educador faz depósitos de conteúdos que devem ser arquivados pelos educandos sem uma reflexão crítica e um posicionamento pessoal sobre tais conteúdos.

O Ministério da Saúde realizou uma discussão sobre o respeito e a valorização da participação e autonomia do sujeito nas ações relativas ao seu bem-estar, superando o modelo de educação linear, ancorado na medicina higienista, na qual a ideologia da cultura comum é substituída pela cultura científica (BRASIL, 2015b). É necessário reconhecer que as líderes estão imersas em uma cultura, na qual o conhecimento científico é considerado superior ao senso comum. Entendemos que a permissibilidade de que os saberes 
populares, intrínsecos à organização comunitária, sejam suprimidos pelo modelo científico faz com que todo o processo sofra prejuízo, no sentido mesmo de um reducionismo. $\mathrm{Na}$ prática, o material utilizado pelas líderes, bem como a forma como a conversa que faz referência ao conhecimento social e cultural é comumente colocada, acaba induzindo à linearidade do repasse de todo este conhecimento.

$\mathrm{Na}$ contracapa do Guia do Líder estão descritas as instituições que participaram da elaboração do Guia, demonstrando que o material foi preparado por profissionais de saúde. Não há menção da participação das líderes e mulheres acompanhadas pela pastoral na organização de conteúdos a serem abordados, partindo das suas necessidades práticas nas comunidades. Em um estudo sobre os cuidados que as mães devem ter com seus bebês prematuros após a alta hospitalar, Fonseca (2004) ressalta a importância da participação das mães e profissionais de enfermagem na elaboração do material, tanto na questão didática como nos conteúdos a serem abordados. Tal pesquisa reuniu esses dois grupos em rodas de discussão onde poderiam falar sobre o que achavam importante aprender e ensinar. A partir das discussões foram definidos os temas geradores para elaboração do material. Após a confecção do material-piloto, este foi validado por profissionais da saúde e pelos participantes da pesquisa, para então ser enviado para confecção final. Dessa maneira, os assuntos abordados eram referentes às necessidades cotidianas das mães alcançando com maior eficácia o público-alvo do material.

As vantagens do aleitamento materno para o bebê e para a mãe, assim como o manejo das técnicas do aleitamento materno, são amplamente comentados em todas as etapas do Guia do Líder e nos panfletos do envelope 'Laços de Amor'.

Segundo o material, o leite materno é o único alimento que o bebê precisa até os seis meses de idade, confirmando a orientação da Organização Mundial da Saúde (OMS), do Fundo das Nações Unidas para a Infância (Unicef) e do Ministério da Saúde do Brasil (MS), que recomendam que a amamentação seja exclusiva nos primeiros 6 meses de vida e complementada até 2 anos de idade ou mais (Brasil, 2015b).

O material mostra-se atualizado nas orientações quanto ao preparo para a amamentação, pois orienta que não se deve passar bucha, toalha áspera ou esticar o bico do seio para fortalecer o mamilo, visto que o próprio organismo da gestante prepara-se para a amamentação. Mostra-se adequado também quando orienta que o leite do peito é completo, não sendo necessário complementar com chá, suco ou água. Em 2015, foi assinado um decreto que regulamenta a Lei 11.265, de 2006, referente à comercialização de alimentos para crianças durante o período da amamentação, proibindo também propagandas de produtos que possam interferir na amamentação (BRASIL, 2015b), reforçando e legitimando a orientação repassada pelas líderes às gestantes. Em todas as visitas que as líderes realizam às gestantes e às mães de bebês que ainda não completaram 6 meses, a informação de que o leite materno é tudo que o bebê precisa para ficar bem alimentado é reforçada, mantendo a mãe segura na decisão em prosseguir com 0 aleitamento materno exclusivo. A superioridade do leite materno em comparação a outras formas de alimentação de crianças até seis meses é citada por inúmeros autores como 
Saliba, et al (2008), entre outros.

Em termos de políticas públicas o aleitamento materno é a forma mais eficaz e barata no combate à mortalidade e morbidade infantil. O Ministério da Saúde (2015b) ressalta que o aleitamento materno permite um grande impacto na saúde integral da mãe e do bebê, revertendo em benefícios para toda a sociedade.

Assim, as mães que optam pelo aleitamento materno exclusivo e obtêm sucesso no manejo, pensando na saúde do seu filho, acabam por 'colaborar' com o plano de estratégias do estado, pois um número menor de crianças e mulheres adoentadas necessitará de atendimento médico/hospitalar. Segundo Giugliani (2000) é difícil quantificar o real impacto social do aleitamento materno, mas estudos confirmam que as crianças alimentadas com leite materno necessitam de menos atendimento médico/hospitalar, diminuindo também a falta dos pais ao trabalho. Kalil e Aguiar (2016), em trabalho realizado sobre discursos pró-aleitamento materno, concluem que se o Estado brasileiro considera a saúde da criança como prioridade, é necessário que as políticas familiares sejam mais efetivas, reforçando a importância da criação e manutenção de uma rede de apoio à mulher para que seja possível a opção pelo aleitamento materno conforme recomendação da OMS.

O Guia apresenta uma descrição completa sobre as várias posições boas para amamentar, a 'boa pega' e os problemas mais comuns na amamentação, como ingurgitamento mamário, rachaduras nos mamilos e mastite, com orientações sobre prevenção e encaminhamentos necessários.

O Guia orienta que a amamentação deve ser agradável para a mãe e para o bebê, assim como sugerem Teruya, Bueno e Serva (2009), quando descrevem que a mãe deve estar relaxada e confortável e o bebê deve estar calmo.

Em relação à boa pega, o Guia descreve, entre outras orientações, que a boca do bebê deve abocanhar todo o mamilo e a maior parte da aréola, estando com o lábio inferior virado para fora e o queixo do bebê encostado na mama. Essas orientações são confirmadas em publicações do Ministério da Saúde como em Brasil (2015b) e em trabalhos como Teruya, Bueno e Serva (2009). Outros dados confirmados por tais estudos que constam no Guia falam sobre retirar o excesso de leite das mamas ingurgitadas antes de oferecer ao bebê, prevenindo a pega incorreta e, consequentemente, problemas como mastite e rachaduras; passar uma ou duas gotas do próprio leite ao redor das aréolas e do mamilo para prevenir rachaduras, sem a necessidade de utilizar outros produtos; amamentar o bebê sempre que este solicitar, respeitando a livre demanda, porém observando se o bebê não está ficando muito tempo sem se alimentar; o mito do leite fraco, reforçando a importância de deixar que o bebê esvazie bem uma mama antes de trocar de seio, pois a composição do leite materno obedece a ordem de descida, iniciando com mais proteína e, ao final da mamada, com mais gordura. Segundo Giugliani (2000) o 'leite fraco' e 'pouco leite' são queixas comuns durante a amamentação e devem ser investigadas, pois podem ser causados tanto por problemas de técnica e manejo da lactação como por questões externas como álcool, fumo, distúrbios emocionais, restrição dietética importante, entre outros. Portanto, afirmar que leite fraco não existe só deve ser sustentado quando, 
após uma avaliação minuciosa demonstrar que a mãe e o bebê apresentam todas as condições adequadas para o processo do aleitamento materno.

Apesar de a sucção ser reflexa, a arte da amamentação é complexa e deve ser ensinada, aprendida e principalmente incentivada, pois vários estudos demonstram que o alto índice de desmame precoce deve-se muito mais a questões externas do que a reais problemas biológicos. Além disso, considerando que o aleitamento materno é uma estratégia de política pública, a valorização e responsabilização não deve estar voltada exclusivamente à mulher sem nenhuma contrapartida. A licença paternidade é uma importante ferramenta de auxílio no aleitamento materno, pois enquanto o pai está em casa em tempo integral é possível que auxilie na organização da rotina para facilitar o momento da amamentação. No Brasil, a licença paternidade de cinco dias é concedida aos homens que trabalham com carteira assinada sob o regime da CLT e servidores públicos. Em março de 2016, no Brasil, foi sancionada a Lei n 13.257 que dispõe sobre as políticas públicas para a primeira infância, alterando as legislações anteriores citadas na publicação (BRASIL, 2016a). Nessa lei foi instituído o Programa Empresa Cidadã, destinado, entre outras questões, a prorrogar por 15 dias a licença-paternidade além dos 5 dias já estabelecidos anteriormente. Entretanto, para que o trabalhador tenha garantido seu direito, deverá requerer no prazo de dois dias úteis após o parto e comprovar participação em programa ou atividade de orientação sobre paternidade responsável. Além disso, somente os trabalhadores sob o regime CLT ou empregado de pessoa jurídica que aderir ao programa terão direito a tal benefício. Em maio de 2016 foi publicado no Diário Oficial da União o decreto no 8.737 que institui a prorrogação da licença paternidade para servidores públicos regidos pela Lei 8.112/90. Para estes servidores a licença paternidade pode ser prorrogada para 15 dias além dos cinco dias concedidos pelo art. 208 da Lei no 8.112, de 1990, caso seja solicitada no prazo de dois dias úteis após o nascimento ou a adoção (BRASIL, 2016b). Apesar de ser considerado um avanço no campo das políticas públicas, ainda muitos homens ficam de fora do benefício, pois somente os trabalhadores com carteira assinada ou servidores públicos têm direito ao benefício, enquanto que o grande número de trabalhadores informais continua sem o direito ao benefício. Segundo Kalil e Aguiar (2016), em alguns países como Suécia e Portugal, já existem licenças parentais, o que torna mais justa a divisão das responsabilidades da criação do filho.

Dessa maneira, a princípio, a responsabilização quanto à saúde dos filhos, principalmente no que diz respeito aos 2 primeiros anos de vida, não estaria exclusivamente depositada sobre a mulher, mas dividida entre pai, mãe e o estado.

O CADERNO DO LÍDER DA PASTORAL DA CRIANÇA E A FOLHA DE ACOMPANHAMENTO E AVALIAÇÃO MENSAL DAS AÇÕES BÁSICAS DE SAÚDE, 
NUTRIÇÃO E EDUCAÇÃO NA COMUNIDADE - FABS.

Esses materiais são utilizados para a coleta dos dados das famílias acompanhadas. Tais instrumentos surgiram como sugestão das próprias líderes no início dos trabalhos da Pastoral da Criança, pois todos os meses eram questionadas sobre os mesmos dados.

O Caderno do Líder da Pastoral da Criança é dividido em quatro partes. A $1^{\text {a }}$ parte, intitulada 'Folha de acompanhamento da criança e da gestante' é onde a líder anota todos os dados da gestante, criança e família acompanhada, coletando informações referentes à saúde, alimentação e desenvolvimento global da gestação/criança até os 6 anos de idade. Essa parte é composta por um questionário estruturado onde o entrevistado está condicionado às perguntas propostas. Esse questionário consiste num conjunto de perguntas que contém respostas geralmente limitadas a um número de possibilidades excludentes e predeterminadas. Por um lado, esta metodologia favorece a padronização e uniformização dos dados coletados, no entanto podem induzir o respondente a escolher uma das respostas apresentadas (GERHARDT; SILVEIRA, 2009).

Nesse item as questões referentes ao aleitamento materno dizem respeito ao tempo de aleitamento materno exclusivo e com que idade a criança começou a receber alguns tipos de alimentos propostos pelo instrumento. Entretanto, não é coletada a informação do motivo que levou a mãe/família a optar pelo desmame, precoce ou não. Os dados coletados pelas líderes deveriam servir para o planejamento de estratégias futuras, entretanto, sem essas informações, as estratégias de incentivo ao aleitamento materno continuam com o direcionamento unilateral, com informações depositadas nas famílias sem responder às reais dificuldades enfrentadas.

Em pesquisa realizada no município de Curitiba-PR por Teter, Oselame e Neves (2015) os principais motivos que levaram ao desmame foram o retorno ao trabalho $(18,33 \%)$ e por considerarem que tinham pouco leite (18,33\%). Segundo Giugliani (2010) os obstáculos para a prática do aleitamento materno incluem vários fatores, dos quais podemos ressaltar a falta de suporte e orientação provenientes de mulheres com experiência em aleitamento materno e o trabalho da mulher. Essa mesma autora ressalta que o tipo de ocupação trabalhista da mulher, o número de horas no trabalho, as leis trabalhistas e o suporte ao aleitamento materno no ambiente de trabalho influenciam diretamente a manutenção do aleitamento materno após o retorno ao trabalho. Kalil e Aguiar (2016) afirmam que problematizar a questão do trabalho feminino e das políticas públicas deveria servir como novas estratégias de incentivo à amamentação e apontam as contradições dos discursos contemporâneos pró-aleitamento materno em relação à política de promoção, proteção e apoio à amamentação.

Em relação ao suporte e orientação proveniente de mulheres com experiência em aleitamento materno na comunidade, citado por Giugliani (2010), a Pastoral da Criança mostra-se como uma opção adequada, visto que muitas das líderes comunitárias são mães e possuem experiências pessoais em aleitamento materno.

$\mathrm{A} 2^{\mathrm{a}}$ parte é denominada 'Registro do não atendimento de criança ou gestante pelo 
serviço de saúde' e deve ser preenchido caso a gestante ou criança tenham apresentado algum motivo para procurar o serviço de saúde. Apesar de não ser um item específico relativo ao aleitamento materno, pode ser utilizado quando a mãe ou o bebê apresentam algum problema referente ao tema e necessitam de atendimento especializado. A líder encaminha ao serviço especializado e aguarda a resposta do atendimento. Caso o atendimento não ocorra, é necessário preencher o motivo alegado para o não atendimento. Esse item pode ser uma ferramenta importante de acompanhamento das dificuldades referentes ao aleitamento materno, visto que em alguns casos, como a mastite, somente o atendimento especializado pode dar o suporte necessário ao binômio mãe/bebê.

A $3^{a}$ parte é referente ao 'Registro de mortes de crianças e mortes maternas', não fazendo parte da análise deste trabalho.

A $4^{a}$ parte, intitulada 'Resumo dos acompanhamentos em casa mês' é composta por um questionário fechado, o mesmo utilizado na FABS, que será discutido abaixo.

A Folha de Acompanhamento e Avaliação Mensal das Ações Básicas de Saúde, Nutrição e Educação na Comunidade - FABS é o instrumento de compilação dos dados coletados em todas as famílias que cada líder deve repassar à coordenadora local. Esta deve preencher a FABS mensalmente com o total de ações realizadas na sua comunidade. É composto por um questionário estruturado, onde são repassadas à coordenação nacional somente os dados pré-estabelecidos por esta. Nesse instrumento a única questão sobre aleitamento materno é referente ao número de crianças que, no mês, completam 6 meses e destas, quantas estão mamando só no peito.

Os dados coletados com tal instrumento são enviados à coordenação nacional da Pastoral da Criança para que sejam enviados ao Ministério da Saúde. Este encaminha recursos financeiros proporcionais ao número de crianças atendidas em cada região. Tais dados poderiam servir também como estratégia de planejamento para projetos e intervenções realizadas pelas líderes. Nas reuniões realizadas mensalmente pelos ramos da Pastoral esses dados poderiam ser discutidos a nível local para traçar estratégias, entretanto essa conduta fica a cargo da coordenação local que pode optar por realizar tal levantamento ou somente encaminhar os dados à coordenação nacional. Algumas campanhas são realizadas a nível nacional pela Pastoral da Criança, mas observa-se que estão relacionadas mais aos acontecimentos atuais, como atualmente o caso da microcefalia, do que aos acontecimentos locais coletados pelos questionários (FABS). Dessa forma perde-se a oportunidade de levantar a demanda solicitada pelas próprias líderes em suas comunidades para dar prioridade ao trabalho de orientação realizado a nível nacional.

\section{CONSIDERAÇÕES FINAIS}

A partir da análise do material utilizado pela Pastoral da Criança, tanto para orientação como para coleta de dados relacionados ao aleitamento materno, pode-se 
destacar o fato destes serem voltados ao conhecimento científico, ainda que sua motivação original fosse em prol de uma organização comunitária e dirigido para a comunidade.

A Pastoral da Criança, enquanto movimento social, atuando em nível local, poderia valer-se da aproximação das pessoas da própria comunidade para aproveitar o seu conhecimento e estratégias de mudanças para planejar ações. Contudo, o que se constata é que o papel singular da líder comunitária não é valorizado. O material utilizado marca uma homogeneização das ações, despersonificando-as e descontextualizando-as da realidade comunitária.

As estratégias utilizadas pela Pastoral da Criança com relação ao aleitamento materno são as mesmas utilizadas pelo Estado, valorizando quase que exclusivamente a questão biológica do leite materno, reforçando a responsabilidade da mulher enquanto fonte do alimento que representa a forma mais eficaz e barata no combate à mortalidade e morbidade infantil. Neste sentido, deixa a entender também que, subjacente às preocupações com a saúde da lactante e seu filho, estão aquelas relacionadas com o controle imbuído nas estratégias de um estado centralizador. Daí porque as padronizações e homogeneizações das cartilhas tomam mais vulto do que as ações locais. Pois, enquanto estas aludem a uma real preocupação com o contexto da lactante, aquelas aludem às tentativas do estado em reduzir custos a médio e longo prazo. Apesar de aparecerem orientações sobre as políticas públicas que as gestantes devem conhecer, fica claro que é preciso muito mais apoio tanto comunitário quanto em termos de políticas públicas, às mulheres que desejam amamentar seu filho exclusivamente até os 6 meses e continuar como complemento até os dois anos de idade. A organização da Pastoral da Criança em grupos pequenos e próximos à comunidade favorece o trabalho de apoio ao aleitamento materno, porém há muito que considerar o papel singular de cada líder e reconhecer seus conhecimentos além do que está posto nos materiais padronizados pela instituição.

\section{REFERÊNCIAS}

ALVES, V.S. Um modelo de educação em saúde para o Programa Saúde da Família: pela integralidade da atenção e reorientação do modelo assistencial. Interface

(Botucatu), Botucatu, v. 9, n. 16, p. 39-52, Feb. 2005.

AKRÉ, J. (Org). Alimentação Infantil: bases fisiológicas. São Paulo: Instituto de Saúde, 1994.

ANJOS, G. Maternidade, cuidados do corpo e "civilização" na Pastoral da Criança. Rev. Estud. Fem., Florianópolis, v. 15, n. 1, p. 27-44, Abr. 2007.

BRASIL. Ministério da Saúde (MS). Política nacional de atenção integral à saúde da mulher - Princípios e Diretrizes. Secretária de Atenção à Saúde, Departamento de Ações Programáticas Estratégicas. Brasília: Ministério da Saúde (MS); 2004.

Ministério da Saúde. Secretaria de Atenção à Saúde. Departamento de Ações Programáticas Estratégicas. Cartilha para a mulher trabalhadora que amamenta / 
Ministério da Saúde, Secretaria de Atenção à Saúde, Departamento de Ações Programáticas Estratégicas. - 2. ed. - Brasília : Ministério da Saúde, 2015. (BRASIL, 2015a)

. Ministério da Saúde. Secretaria de Atenção à Saúde. Departamento de Atenção Básica. Saúde da criança: aleitamento materno e alimentação complementar / Ministério da Saúde, Secretaria de Atenção à Saúde, Departamento de Atenção Básica. 2. ed. - Brasília : Ministério da Saúde, 2015. (BRASIL, 2015b)

Presidência da República. Casa Civil. Subchefia para Assuntos Jurídicos. Lei no 13.257, de 8 de março de 2016. Dispõe sobre as políticas públicas para a primeira infância e altera a Lei no 8.069, de 13 de julho de 1990 (Estatuto da Criança e do Adolescente), o Decreto-Lei no 3.689, de 3 de outubro de 1941 (Código de Processo Penal), a Consolidação das Leis do Trabalho (CLT), aprovada pelo Decreto-Lei no 5.452, de 1ㅇ de maio de 1943, a Lei no 11.770, de 9 de setembro de 2008, e a Lei no 12.662, de 5 de junho de 2012. 2016. (BRASIL, 2016a)

Presidência da República. Casa Civil. Subchefia para Assuntos Jurídicos. Decreto no 8.737, de 3 de maio de 2016. Institui o Programa de Prorrogação da LicençaPaternidade para os servidores regidos pela Lei $n=8.112$, de 11 de dezembro de 1990. 2016. (BRASIL, 2016b)

COSTA, G.D.; COTTA, R.M.M.; REIS, J.R.; BATISTA, R.S.; GOMES, A.P.; FRANCESCHINI, S.C.C. Avaliação do cuidado à saúde da gestante no contexto do Programa Saúde da Família. Cien Saude Colet, v. 14, Supl. 1, p. 1347-1357, 2009.

CUNHA, A.J.; LEITE, A.J.; ALMEIDA, I.S. The pediatrician's role in the first thousand days of the child: the pursuit of healthy nutrition and development. Jornal de Pediatria, Rio de Janeiro, n 91, p. 44-51, 2015.

FONSECA, L.M.M.; et al . Cartilha educativa para orientação materna sobre os cuidados com o bebê prematuro. Rev. Latino-Am. Enfermagem, Ribeirão Preto, v. 12, n. 1, p. 6575, Fev. 2004.

FREIRE, P. Pedagogia do oprimido. 12ª ed. Rio de Janeiro: Paz e Terra, 1983.

GERHARDT. T.E.; SILVEIRA, D.T. (Org.). Métodos de pesquisa. Coordenado pela Universidade Aberta do Brasil - UAB/UFRGS e pelo Curso de Graduação Tecnológica Planejamento e Gestão para o Desenvolvimento Rural da SEAD/UFRGS. - Porto Alegre: Editora da UFRGS, 2009.

GIUGLIANI, E.R.J. O aleitamento materno na prática clínica. Jornal de Pediatria. Vol. 76, Supl.3, 2000.

E.R.J. Amamentação exclusiva. In: CARVALHO, MR. (Org.) Amamentação - Bases Científicas. 3a ed. Rio de Janeiro, Guanabara Koogan, 2010.

GONÇALVES, C.V.; CESAR, J.A.; SASSI, R.A.M. Qualidade e equidade na assistência à gestante: um estudo de base populacional no Sul do Brasil. Cad Saude Publica, v. 25, n. 11, p. 2507-2516. 2009.

KALIL, IR, AGUIAR, AC. Trabalho feminino, políticas familiares e discursos pró- 
aleitamento materno: avanços e desafios à equidade de gênero. Saúde em Debate, Rio de Janeiro, no prelo. 2016. Disponível em http://www.saudeemdebate.org.br/artigos/ artigo_int.php?id_artigo=4099. Acesso em: 16 ago. 2016.

MINAYO, M.C.S. O desafio do conhecimento. Pesquisa qualitativa em saúde. São Paulo: Hucitec; Rio de Janeiro: ABRASCO; 2000.

PASTORAL DA CRIANÇA. Lições da Pastoral da Criança: entrevista com Zilda Arns Neumann. Estud. av., São Paulo , v. 17, n. 48, p. 63-75, Ago. 2003.

Curitiba: il.color, 2015.

Guia do Líder da Pastoral da Criança: para países de língua portuguesa.

RIOS, C.T.F; VIEIRA, N.F.C. Ações educativas no pré-natal: reflexão sobre a consulta de enfermagem como um espaço para educação em saúde. Cienc Saude Colet., v. 12, n. 2, p. 477-486. 2007.

SALIBA, N. A.; et al . Freqüência e variáveis associadas ao aleitamento materno em crianças com até 12 meses de idade no município de Araçatuba, São Paulo, Brazil. Rev. Bras. Saude Mater. Infant., Recife , v. 8, n. 4, p. 481-490, dez. 2008.

SILVA, R.M.; et al . Cartografia do cuidado na saúde da gestante. Ciênc. saúde coletiva, Rio de Janeiro, v. 17, n. 3, p. 635-642, mar. 2012.

TERUYA, K; BUENO, L.G.S.; SERVA, V. Manejo da lactação. In: REGO, J.D. Aleitamento Materno. $2^{\circ}$ Ed, Atheneu. São Paulo, 2009.

TETER, M.S.H.; OSELAME, G.B.; NEVES, E.B. Amamentação e desmame precoce em lactantes de Curitiba. Revista Espaço para a Saúde, Londrina, v. 16, n. 4, p. 55-63, out/dez. 2015. 